\title{
El grupo familiar de Juan Gil Patricio Morlete Ruiz, pintor novohispano
}

A la fecha, la figura de Juan Gil Patricio Morlete Ruiz no cuenta con un amplio estudio monográfico, a pesar de estar considerado con José de Páez, Francisco Antonio Vallejo, José Ventura de Arnáez, José de Alcibar y Manuel de Osorio, entre otros, uno de los grandes pintores de la segunda mitad del siglo XVIII, lo cual permite pensar que nos encontramos ante un pintor todavía desconocido. Llama la atención que, al realizar una búsqueda sobre él en obras básicas de referencia, su nombre no aparece en el Diccionario biográfico mexicano ${ }^{\mathrm{I}}$ de Miguel Ángel Peral ni en el "Apéndice" ${ }^{2}$ al mismo, como tampoco en el Diccionario biográfico y de historia de México ${ }^{3}$ de Juan López de la Escalera y Sánchez. La Enciclopedia de México ${ }^{4}$ recoge una biografía muy breve con las fechas extremas de I7I5-I770, mismas que se contienen en el Diccionario enciclopédico de México ${ }^{5}$ de Humberto Musacchio, frente al Diccionario Porrúa de historia, biografía y geografía de México, ${ }^{6}$ el cual ofrece las de I7I3-I772.

I. Miguel Ángel Peral, Diccionario biográfico mexicano (México: PAC, I944).

2. Peral, "Apéndice", Diccionario biográfico mexicano.

3. Juan López de la Escalera y Sánchez, Diccionario biográfico y de historia de México (México: Petróleos Mexicanos, I98I).

4. Enciclopedia de México, t. X (México: Enciclopedia de México/Secretaría de Educación Pública, I988), 5635.

5. Humberto Musacchio, Diccionario enciclopédico de México, vol. 3 (México: Distribuidora de Ediciones Pedagógica, 1989), I303.

6. Diccionario Porrúa de historia, biografía y geografía de México, 6a ed., vol. 3 (México: Porrúa, I995), 2377. 
Esta primera divergencia de información sobre las fechas de nacimiento y muerte aparece como una constante en la bibliografía disponible, como tendremos ocasión de ver. Este asunto, si bien muestra un margen de pocos años de diferencia, no es trivial cuando se trata de informar cuándo nace y muere determinado personaje en estudio.

Uno de los últimos trabajos específicos sobre el pintor se debe a Óscar Reyes-Retana Márquez, quien en 1996 publicó un artículo que revelaba la existencia de una serie de paisajes pintados por Morlete, localizados entonces en el Palacio de San Antón, residencia de verano de los presidentes de Malta.7 No obstante la importancia del hallazgo, Reyes-Retana no aportó datos específicos sobre la vida de Morlete, salvo que la serie presentada se pintó entre I769 y I77I y probablemente se trató de un encargo del virrey Bucareli. Tal encargo se adjudica a los seis paisajes pintados por Morlete y adquiridos por Los Angeles County Museum of Art con fondos de la colección Bernard and Edith Lewin, y presenta vistas de la villa y rada de Tolón, el puerto viejo de Tolón, la villa y puerto de Bayona (dos), el puerto de Sète y el puerto de Antibes, todas tomadas de la serie realizada por Claude Joseph Vernet (I7I4-I789) sobre los puertos franceses, ${ }^{8}$ que muestran diferencias frente a los de Malta en la cartela explicativa al llevar la serie adquirida por el Museo de Los Ángeles las armas reales.

Durante el proceso de investigación y conformación del banco de información sobre familias novohispanas desarrollado en el Instituto de Investigaciones Históricas de la Universidad Nacional Autónoma de México, ${ }^{9}$ aparecieron algunas actas sacramentales de la familia Morlete, con lo cual surgió la idea de rastrear más profundamente a su grupo familiar y contribuir con ello al conocimiento de una parcela de la vida de este importante pintor novohispano. Como resultado de ello, el presente trabajo tiene un doble obje-

7. Óscar Reyes-Retana Márquez, "Las pinturas de Juan Patricio Morlete Ruiz en Malta", Anales del Instituto de Investigaciones Estéticas I7, núm. 68 (I996): I I3-I25.

8. El video relativo al proceso de restauración de los cuadros incluye la mención de éstos en los inventarios postmortem del virrey (www.youtube.com/watch?v=s7VI2JNKSOQ). Llama la atención que si bien las fechas extremas del pintor son correctas en las fichas catalográficas contenidas en la dirección electrónica del museo (http://collections.lacma.org), varios artículos derivados de la misma dan como fecha final de la vida del pintor la de I78I. Cf. http://lacma. wordpress.com/2013/04/25/a-collaborative-venture-the-conservation-of-morletes-ports-offrance/ y http://www.lacma.org/sites/default/files/Latin-American-reinstallation-Press-Release-3.20.I3 FINAL_o.pdf

9. http://gw.geneanet.org/sanchiz 
tivo: en primer lugar, recoger y presentar bibliográficamente cómo se realizó la construcción de la biografía sobre el pintor novohispano, lo cual a su vez permite establecer la triple periodización que se dio en el avance del conocimiento sobre Morlete, y en segundo lugar, aportar la reconstrucción de su familia a través de la genealogía, campo y disciplina que permiten establecer de forma certera, además de la extensión del grupo familiar, las fechas extremas de nacimiento y muerte del pintor, así como las relaciones de afinidad desarrolladas por Morlete Ruiz con algunos individuos de su entorno. No es objetivo de la presente recopilación realizar una reflexión teórica ni profundizar en el personaje como uno de los actores sociales de su momento. ${ }^{\text {IO }}$

\section{La búsqueda bio-bibliográfica sobre Juan Gil Patricio Morlete Ruiz}

$$
\text { Los pioneros (I864-I893) }
$$

Hasta donde he podido averiguar, Rafael Lucio, en su Reseña histórica de la pintura mexicana en los siglos XVII y XVIII, es uno de los primeros en mencionar al pintor, si bien lo llama Patricio Morlet, del cual, junto a otros contemporáneos, dice: "pintaban a la manera de Cabrera, pero eran inferiores a él". II Gracias a Lucio y a José Bernardo Couto, con su trabajo publicado en I872, Diálogo sobre la historia de la pintura en México, ${ }^{\mathrm{I} 2}$ contamos con un incipiente repertorio de los más destacados pintores de los siglos XVII y XVIII en México. Si bien el primero de ellos no hablaba de ninguna de sus obras, Couto, por su parte, al realizar uno de sus recorridos en el libro, mencionaba: "ClAvÉ: Aquí tenemos de Juan Patricio Morlete Ruiz ese pequeño cuadro de San Luis Gonzaga, que no carece de agrado. En el Carmen, antes de la librería, hemos

Io. Agradezco profundamente a los dictaminadores del presente trabajo su lectura crítica y sus valiosas aportaciones y precisiones, las cuales permitieron enriquecer la presente recopilación.

I I. Rafael Lucio, Reseña histórica de la pintura mexicana en los siglos XVII y XVIII, Biblioteca de Historiadores Mexicanos (México: Vargas Rea, I953 [1864]), 33 y 38.

I2. José Bernardo Couto, Diálogo sobre la historia de la pintura en México, ed., pról. y notas Manuel Toussaint (México: Biblioteca Americana, 1947), 105. La primera edición se realizó en I872 en México en la Imprenta de Escalante. Existe asimismo una edición posterior con estudio introductorio de Juana Gutiérrez Haces y notas de Rogelio Ruiz Gomar (México: Consejo Nacional para la Cultura y las Artes, I995), II7. 
visto el señor Couto y yo cuadros suyos alegóricos, que es género a que parece que era inclinado". ${ }^{\mathrm{3}}$

Años después, Manuel G. Revilla, en Visión y sentido de la plástica mexicana,${ }^{\mathrm{I} 4}$ indudablemente siguiendo a Lucio lo trajo a colación al tratar del estilo de Miguel Cabrera, adjudicándole menor personalidad que la de Vallejo y Alcíbar. Posteriormente, Juan José Tablada también recogió la presencia de Morlete en su Historia del arte en México, limitándose prácticamente a decir que "son pocas las obras que se conservan de este artista". Is

En resumidas cuentas, lo que se conocía de él hasta I893 muestra básicamente su predilección por la pintura religiosa, alegórica, y aparentemente el tener una producción limitada o poco conocida. ${ }^{16}$

\section{Los académicos de Estéticas en la primera mitad del siglo xx}

A Francisco de la Maza se debe la noticia publicada en 1939 del nacimiento de Morlete Ruiz en San Miguel el Grande, hoy San Miguel de Allende, Guanajuato; ${ }^{17}$ obtuvo esta información gracias a la lectura de una copia del testamento que le facilitó el ingeniero Enrique A. Cervantes, sin proporcionar el nombre del escribano ante el cual se formalizó. ${ }^{18}$

I3. En la edición mencionada en la nota anterior y anotada por Rogelio Ruiz Gomar, se precisaba correctamente que "Juan Patricio Morlete Ruiz era originario de la actual población de San Miguel Allende, nació en I7I3 y murió en I772. Ahora sabemos que fue discípulo de Ibarra y no de Cabrera como se venía diciendo. El San Luis Gonzaga que se hace mención se conserva en la Pinacoteca Virreinal" [Cabe actualizar que dicha obra pasó posteriormente al Museo Nacional de Arte].

I4. Manuel G. Revilla, Visión y sentido de la plástica mexicana, ed. Elisa García Barragán, $2^{\mathrm{a}}$ ed. (México: Universidad Nacional Autónoma de México, 2007 [I893]), I55 (México: Librería Universal de Porrúa Hermanos, I923), 54.

I5. Juan José Tablada, Historia del arte en México (México: Manuel León Sánchez, I927), I42.

I6. Hay que tomar en cuenta estos pequeños antecedentes historiográficos, como los que propiciaron la aparición del Catálogo inédito de Mateo Herrera, director de la Academia de San Carlos (ca. I9I8), quien asimismo hará unas breves observaciones críticas de la pintura de Morlete, como recogen, entre otros autores, Xavier Moyssén, Rogelio Ruiz Gomar y Carmen Andrade.

I7. Francisco de la Maza, San Miguel de Allende: su historia, sus monumentos (México: Frente de Afirmación Hispanista, 1972), 195. La información se repetiría en su obra El arte colonial en San Luis Potosi (México: Universidad Nacional Autónoma de México, 1985).

I8. Soy consciente de que la figura del ingeniero Enrique A. Cervantes, como transmisor 
Creo, no obstante las anteriores aportaciones, que podemos considerar a Manuel Toussaint como el principal contribuyente en la biografía escalonada de Juan Gil Patricio Morlete Ruiz para la historiografía. Sus pequeños apuntes al respecto, publicados primero en la anotación que hizo a la obra de Couto ya referida, fueron retomados en el libro Arte colonial en México ${ }^{19}$ y posteriormente ampliados de forma notoria, como tendremos ocasión de ver, en La pintura colonial. Los primeros se limitaban, no obstante, a decir:

Don Juan Patricio Morlete Ruiz. Sabemos que nació en I7I 5; se casó muy joven con dońa María Careaga, de quien tuvo muchos descendientes. La figura de este artista en extremo simpática, coincide con sus obras, dotadas de una discreción rara en su época, aunque no pueda independizarse de ella, prefiere los tonos grises plateados en que se destaca la morbidez de los rostros, sobre todo de San Luis Gonzaga, que él pintó con preferencia. Sus obras no son abundantes; citemos los retratos de los virreyes Amarillas, Cajigal y Croix, que existen en el Museo de Historia de Chapultepec. ${ }^{20}$

A partir de la información recabada por Manuel Toussaint sobre Morlete y si bien ésta se encontraba inédita, Agustín Velázquez Chávez, en su obra Tres siglos de pintura colonial mexicana, ${ }^{21}$ la había dado a conocer años

del conocimiento, y su labor de localización de documentos relativos a la historia del arte en México requerirían un estudio mayor. No descarto que gracias a él muchos de sus colegas en Investigaciones Estéticas dispusieran de los primeros datos biográficos sobre Morlete. Respecto de su trascendencia véase el artículo de Francisco Vidargas, "Enrique A. Cervantes: recuerdo", en textosdispersos.blogspot. $\mathrm{mx} / 2007 / \mathrm{or} / \mathrm{enrique-cervantes-recuerdo.html}$

19. Manuel Toussaint, Arte colonial en México (México: Universidad Nacional Autónoma de México-Instituto de Investigaciones Estéticas, I948), I67-I68.

20. Toussaint, Arte colonial en México, 167. En opinión del historiador Pedro Ángeles, a quien agradezco la lectura previa del presente trabajo y sus observaciones, los calificativos de "figura simpática" y "discreción rara" utilizados por Toussaint, dejan entrever que Toussaint, si bien carecía de elementos para una mayor profundidad de análisis, era consciente de su importancia.

2I. Agustín Velázquez Chávez, Tres siglos de pintura colonial mexicana (México: Polis, 1939), 323-324. Agradezco a Rogelio Ruiz Gomar no sólo la referencia bibliográfica de esta obra, sino sus atinados comentarios y precisiones al borrador del presente estudio. Velázquez Chávez enjuiciaba la pintura de Morlete en los siguientes términos: "Su pintura de composición artificiosa, de trazo y colorido suave, de luces vivas, trae a la memoria una cierta tendencia mexicana, ingenua y grotesca que encontramos en la mayoría de los pintores de mediados de este siglo”. La breve reseńa biográfica se acompañaba de la mención de tres retratos que albergaba el Museo Nacional de Historia, otros cinco en la Escuela de Artes Plásticas y uno más en las Galerías de la Granja. 
antes. ${ }^{22}$ En su libro no queda la menor duda de la filiación de la información de Toussaint, como tampoco de la frecuente comunicación entre los académicos e historiadores del arte de aquellos años sobre los nuevos hallazgos, tanto de obra como de datos biográficos.

Dentro del grupo de académicos que formarían el Instituto de Investigaciones Estéticas y al cual pertenecieron De la Maza y Toussaint, también su colega Manuel Romero de Terreros, en El arte en México durante el virreinato, resumen histórico, ${ }^{23}$ aumentaría algo más la información sobre Morlete, dando un año de defunción, su característica de copiar pinturas europeas de maestros renombrados, haber sobresalido como retratista y haber sido segundo director de la Academia de Pintura. ${ }^{24}$

22. "Según datos que ha recabado don Manuel Toussaint, este artista nació en I7I5; se casó joven con doña María Areaga, de quien tuvo varios hijos, y parece que aún vivía cuando fue fundada la Academia [es decir, en I78I], pero esto no está comprobado. Por las fechas que aparecen en sus obras es posible que haya fallecido en el decenio de 1770 aun cuando tampoco existen datos ciertos de ello”. La ficha biográfica que elaboró Velázquez Chávez volvería a publicarse en "La pintura colonial en Hidalgo", en Tres siglos de pintura colonial mexicana (México: Gobierno del Estado de Hidalgo, I986) 589-590. El autor informaba en su libro que había noticias de haber pintado en I77 I el retrato del obispo Vicente Díaz Bravo.

23. Manuel Romero de Terreros, El arte en México durante el virreinato, resumen histórico (México: Porrúa, 195I), 65.

24. "Juan Patricio Morlete Ruiz nació en I7Is y murió en I790. Muy joven se casó con dońa María de Careaga y tuvo numerosa descendencia. Su pintura es, en general, discreta, pues si incurrió en los mismos defectos de Cabrera, fue en mucho menor escala. Gustaba de pintar composiciones alegóricas y de copiar pinturas europeas de maestros famosos, como Van Dyck y Rubens, valiéndose de grabados; pero sobresalió como pintor de retratos. Fue el segundo director de la Academia de Pintura." Respecto a los retratos elaborados por Morlete —relativos a los virreyes Agustín de Ahumada Villalón, marqués de las Amarillas, Francisco Cajigal de la Vega y Carlos Francisco de Croix, existentes en el Museo Nacional de Historia de Chapultepec- que ya habían consignado Agustín Velázquez Chávez y Toussaint, en La enciclopedia de México, recogen además el de Manuel de Aldaco conservado en el Colegio de las Vizcaínas. En relación con este último retrato, ya Gonzalo Obregón, en El Real Colegio de San Ignacio de México (Las Vizcainas) (México: El Colegio de México, 1949), 49, había identificado la autoría del mismo, y es probable que publicar el dato poco después de la edición de la obra de Velázquez y de Toussaint fuera la causa de que no lo mencionaran ambos. Sobre dichos retratos véase además María Esther Ciancas y Bárbara Meyer, La pintura de retrato colonial (siglos XVI-XVIII) (México: Instituto Nacional de Antropología e HistoriaMuseo Nacional de Historia, I994), I8, 32 y 49, y Justo Gárate Arriola y J. Ignacio Tellechea Idígoras, El Colegio de las Vizcainas de México y el Real Seminario de Vergara (Vitoria-Gasteiz: Eusko Jaurlaritza, I992), 62. 
EL GRUPO FAMiliar DE JUAN GiL PATRICIO MORLETE RUIZ 205

Morlete Ruiz a partir de la segunda mitad del siglo xx

La aparición de nuevas obras y la difusión de los espacios museográficos que las albergan parecen haber estimulado sobremanera los estudios sobre Morlete en esta tercera etapa. La novedad y calidad de la información biográfica sobre el pintor ha tenido serios altibajos en el periodo y frente a una masiva repetición de datos no son tan numerosos los casos de nuevas aportaciones.

Los primeros acercamientos a la extensión del grupo familiar de Morlete Ruiz que permitieron pasar de "los muchos hijos" mencionados por Toussaint salieron a la luz gracias a la labor de búsqueda documental que elaboró Salvador Cruz en el artículo "Algunos pintores y escultores de la ciudad en el siglo XVIII (según padrones del Sagrario Metropolitano)”. ${ }^{25}$ Cruz localizó la vivienda de Morlete en la feligresía del Sagrario de la Asunción de la ciudad de México, en el padrón realizado en I753, la cual se encontraba en la "Cera de enfrente del arquillo que vuelve para la Casuela, en una casa alta donde vivía con María Josefa Cariaga, y sus hijos: María de Jesús, María Antonia, María Máxima Rosalía y Ramón”.

La explotación de la misma fuente documental permitió averiguar que en I767 su vivienda se localizaba en el callejón del Arquillo de la Profesa, recogiéndose ese año en el domicilio a María Josefa (Cariaga) Medina, María de Jesús Morlete, María Micaela, María Josefa, María Ignacia, María Andrea, María Isabel, Francisca, José, José Antonio, Francisco y Martín Vicente. Desgraciadamente el autor no da mayores referencias documentales por tratarse de un padrón de un archivo particular. ${ }^{26}$ Cabe la duda, por la reconstrucción familiar realizada al final de este trabajo, de que algunos de los mencionados fueran parte de la familia extensa del pintor: empleados u otras personas que vivieran bajo el mismo techo. ${ }^{27}$

25. Salvador Cruz, "Algunos pintores y escultores de la ciudad en el siglo XviII (según padrones del Sagrario Metropolitano)", Anales del Instituto de Investigaciones Estéticas 9, núm. 33 (1964): 105.

26. "Padrón que para cumplimiento de NSM Iglesia hizo SLD Carlos Celedonio de Velázquez, como cura del Sagrario de dicha Santa Yglesia, comensado en quatro de marzo del ańo de 1767 ", I vol., manuscrito sin foliar.

27. La relación del grupo familiar de Juan Patricio Morlete de 1753 volvería a aparecer en el trabajo de Eduardo Báez Macías, Boletín del Archivo General de la Nación, segunda serie, t. VIII (México: 1967), 984, n. 3-4, bajo la entrada de Ruiz, Juan Patricio. En esa ficha se aclaraba que los hijos varones eran "Juan de i 8 años, José de 6, Francisco de 2 " y había cinco 
En la anotación al registro, Salvador Cruz dejó constancia de que "se comprueba la numerosa descendencia de Morlete Ruiz y ahora sabemos el segundo apellido de su esposa".

No obstante que esta información salía publicada en 1965, parte de ella ya había sido localizada por Toussaint, aproximadamente en el transcurso de los años cuarenta y cincuenta, y la dejó consignada en su libro Pintura colonial. Toussaint había concluido su obra en 1954, pero quedó inédita por haber fallecido en $1955 .{ }^{28}$ Fue en 1965 cuando la publicó el Instituto de Investigaciones Estéticas y, por tanto, a partir de entonces podemos hablar de la influencia que ejerció en los escritos sobre Morlete aparecidos años después. La reescritura de la ficha biográfica creció sobremanera sobre todo con la nueva obra aparecida y consignada al tratar de los pintores de la Maravilla americana:

Juan Patricio Morlete Ruiz. Este simpático pintor forma con Alcíbar la más interesante pareja del grupo. De su papeleta formada en el padrón de la ciudad de México, en I753, se sacan las siguientes informaciones: nació en I7 I 5; estaba casado con María Careaga, y debe haberlo hecho cuando era aún muy joven, pues en ese ańo de 1753 tenía ya ocho hijos, tres varones: Juan de i 8 años, José de 6, Francisco de 2 y cinco mujeres llamadas todas María con las edades respectivas de I I, Io, 9 y 8 años y la última de dos meses. La criada era mestiza, doncella y tenía i 8 ańos. La casa del pintor estaba en el centro de la Alcaicería, comenzando por la entrada de Tacuba, sobre la mano derecha de norte a sur. Ignoro si sería pariente suyo el pintor Mariano Morlete que firma algunos cuadros que existen en el Carmen de Puebla, así como si un doctor Juan Patricio Morlete que había muerto en I774, sería su primer hijo, y si su segundo sería el José Morlete que firma el retrato de la segunda Condesa de Regla, fechado en I 775 y copiado en 1789, que posee el descendiente de esta señora, marqués de San Francisco. Dada la inveterada costumbre de que los hijos siguieran el oficio de los padres, que, como repetidas veces hemos visto, daba lugar a la formación de verdaderas dinastías de pintores, no sería nada difícil que todos estos Morletes descendieran de Juan Patricio.

Se conservan noticias de bastantes obras de Morlete Ruiz. Couto dice que en el Carmen de México, antes de la librería, se miraban varios lienzos suyos de temas alegóricos. En las Galerías de Pintura existen los siguientes cuadros:

hijas de nombre María “de i I, Io, 9, 8 años y 2 meses. Todos españoles”. En el domicilio vivía asimismo una criada mestiza de 18 años llamada Máxima.

28. En dicha edición se menciona que la obra se finalizó en I934, en lugar de i954, lo cual considero un error tipográfico. Toussaint, para 1934, no estaba en posibilidad de presentar muchos datos, resultado de esta biografía escalonada que recoge el presente trabajo. 
EL GRUPO FAMILIAR DE JUAN GiL PATRICIO MORLETE RUIZ 207

El corazón de Jesús rodeado de santos, I759; San Luis Gonzaga; La Purísima; Jesús consolado por los Ángeles; el Corazón de María rodeado de santos. La Alacena con objetos varios, que se atribuía a Morlete, está firmada por Pérez de Aguilar. En Tepoztlán se guarda un San Luis Gonzaga. Morlete Ruiz firma los retratos de los siguientes virreyes en la colección del Museo: Marqués de las Amarillas (1755-1760); D. Francisco Cagigal (1760) y Marqués de Croix (I766-I77I). En la Decimosexta Exposición de Bellas Artes se exhibió una Virgen del Rosario que pertenecía al obispo Madrid, y en la iglesia de Mitla en Oaxaca, donde existen las famosas ruinas, se conserva un San Isidro Labrador. El señor Romero de Terreros posee un San Agustín y don Salvador Ugarte una Piedad fechada en I737, es decir, una de sus primeras obras. Parece inspirada en un cuadro del Divino Morales, pero su ejecución es en extremo mediocre. Finalmente en una casa de antigüedades he visto dos cuadros que representan batallas: uno, la Entrada de Constantino en Roma, fechado en 1766, y el otro un Combate de Aníbal.

Se ha dicho que Morlete Ruiz alcanzó la fundación de la Academia de San Carlos en I78I, como Alcíbar y Vallejo. Esto no es exacto, o, al menos no está comprobado. Es más de creerse que moriría en el decenio del 70, dadas las fechas de sus obras.

Fue Morlete pintor distinguido; algunos lo consideran superior al mismo Cabrera. Mateo Herrera en su Catálogo inédito, se expresa así de este artista: "Cuando se abusaba tanto de las coloraciones falsas y chillonas y del dibujo flojo y sin expresión, Morlete Ruiz presenta el raro caso de dibujar correctamente y de pintar sus obras con sobriedad, en una entonación gris, no exenta de buen gusto". ${ }^{29}$

La anterior reelaboración biográfica pronto tuvo seguidores durante los años siguientes, tal como se comprueba en el trabajo que publicó José Rojas Garcidueñas en la revista Anales al tratar de una pintura de la Virgen de Guadalupe conservada en la catedral de Santiago de Compostela; ${ }^{30}$ en la breve biografía

29. Manuel Toussaint, Pintura colonial en México (México: Universidad Nacional Autónoma de México, 1965), I67-I68. Notable fue la reedición y anotación de esta obra realizada por Xavier Moyssén (México: Universidad Nacional Autónoma de México-Instituto de Investigaciones Estéticas, 1982), 268, donde consigna varias obras más de Morlete, tanto de retratos como de tema religioso, algunas localizadas por Francisco de la Maza. De los retratos mencionados, el del licenciado Antonio de Padilla y Rivadeneyra, conservado en la iglesia de Tlalnepantla, ya había sido anunciado años antes por Ernesto Sodi Pallarés, Pinacoteca Virreinal de San Diego, Populibros (México: La Prensa, I969), I50.

30. José Rojas Garcidueńas, "Un óleo mexicano en Santiago de Compostela”, Anales del Instituto de Investigaciones Estéticas 9, núm. 34 (1965): 72-73. 
que elaboró Heriberto García Rivas; ${ }^{31}$ en la ficha que hizo Carmen Andrade al tratar de los pintores de la antigua Pinacoteca Virreinal, ${ }^{32}$ y en la de María Concepción García Saiz aparecida en el catálogo La pintura colonial en el Museo de América: la escuela mexicana. ${ }^{33}$

Respecto a la identificación de la obra de Morlete, destaca que a finales de la década de los setenta, Eduardo Báez Macías publicó en su Guía del Archivo de la Antigua Academia de San Carlos I844-1867 la relación de los cuadros conservados en la academia, donde aparecía nuevamente la referencia al retrato de san Luis Gonzaga ${ }^{34}$ y la del retrato del obispo de Puebla, Juan de Palafox y Mendoza, en la colección del convento de la Encarnación. ${ }^{35}$

Por su parte, José Ignacio Conde y María Teresa Cervantes, en el capítulo "Nuestra Señora de Guadalupe en el arte", del Álbum del 450 aniversario de las apariciones de Nuestra Señora de Guadalupe, ${ }^{36}$ si bien continuaron ofreciendo los mismos datos de Toussaint de 1965, aportaron el análisis de una de las imágenes de la Virgen de Guadalupe recogidas por González Moreno (tomo I de Iconografía guadalupana), de gran tamaño, fechada en I763, que se conservaba en el coro de la iglesia parroquial de Santa María de Ulibarri en Durango, Vizcaya, y sacaron a la luz otra de las representaciones de la Virgen de Guadalupe, autoría asimismo de Morlete, fechada en I76I, basada en la lámina del grabador alemán José Sebastián Klauber. ${ }^{37}$

La publicación en 1989 del catálogo Tesoros de la Pinacoteca Virreinal ${ }^{38}$ de Virginia Armella de Aspe y Mercedes Meade de Angulo, miembros de la

31. Heriberto García Rivas, Pintores mexicanos 150 biografías (México: Diana, 1965).

32. Carmen Andrade, La Pinacoteca Virreinal (México: Secretaría de Educación Pública, I974), I28. Esta autora volvió a consignar la misma información en el número monográfico sobre la Pinacoteca Virreinal de San Diego, publicado por Artes de México, año XXII (México, I976): 67, n. I88.

33. María Concepción García Sáiz, La pintura colonial en el Museo de América: la escuela mexicana, vol. I (Madrid: Museo de América, 1980), 86.

34. Eduardo Báez Macías, Guía del Archivo de la antigua Academia de San Carlos I844I867 (México: Universidad Nacional Autónoma de México, 1976), 315, ficha 6505.

35. Báez Macías, Guía del Archivo de la Antigua Academia de San Carlos I844-1867, 330, ficha $654 \mathrm{I}$.

36. Álbum del 450 aniversario de las apariciones de Nuestra Señora de Guadalupe (México: Buena Nueva, I98I), I54.

37. Álbum del 450 aniversario, 159.

38. Virginia Armella de Aspe y Mercedes Meade de Angulo, Tesoros de la Pinacoteca Virreinal (México: Mercantil de México, I989), I91. 
Academia Mexicana de Genealogía, supuso la mayor aportación biográfica y de filiación del pintor aparecida hasta entonces:

En la iglesia parroquial de San Miguel el Grande, el día I4 de febrero de I708, se casaron Nicolás de Morlete, español y Manuela Ruiz, india. Fueron sus padrinos Ventura de Mendoza y su hermana, María de Mendoza, mulatos libres. Por el acta anterior conocemos que Juan Patricio fue mestizo; nació en I7I3 y llegó a la ciudad de México en I729, y cuatro años más tarde, contando apenas 20 de edad, casó con Josefa Careaga. En el acta correspondiente del Sagrario, Juan Patricio figura como español y su esposa es también española, natural y vecina de México, hija legítima de Nicolás de Careaga y Gertrudis Osorio. La boda se celebró en casa del maestro pintor don José de Ibarra en la calle de la Pacha de la ciudad de México. En el padrón de 1753 aparece Juan Patricio: español, pintor, de 38 años, casado con María Careaga, con los hijos siguientes: Juan de i8 años; José de seis; Francisco, de dos: cinco hijas de nombre María de II, Io, nueve, ocho y dos meses respectivamente; todos españoles. Vive en la Alcaicería. Su criada se llama Máxima, de I8 años.

No existe el acta de defunción de María Josefa Careaga, pero Juan Patricio contrajo segundo matrimonio con dońa Josefa Medina Granados, española, natural y vecina de México, hija legítima de Joaquín Medina Granados y doña Ana de Sevilla, el 4 de julio de I762. De sus hijos sabemos que don José Antonio Morlete Ruiz, español, soltero, natural y vecino de México, casó el 8 de septiembre de I770 con María Josefa Vázquez, española, hija legítima de don Martín Vázquez y doña Josefa Torres, el 8 de septiembre de I770. Murió en 1772.

A principios de la década de los ańos noventa, Salvador Gómez Eichelmann, al tratar al pintor en su obra Historia de la pintura en San Luis Potosí, ${ }^{39}$ ensalzó sus características pictóricas y su minuciosidad y ofreció un buen compendio del conocimiento sobre el pintor difundido hasta entonces, además de algunos ejemplos de sus obras localizadas en San Luis Potosí aún no divulgadas. También nuevas ubicaciones de obra surgieron en esos años en España, como difundieron María Teresa Terrón Reynolds y Moisés Bazán Huerta 
en el artículo "Obras de arte inéditas en conventos de Plasencia",40 quienes localizaron otra imagen de la Virgen de Guadalupe en el convento de Clarisas Capuchinas de dicha ciudad.

En el avance biográfico sobre el pintor, el equipo conformado por Glorinela González Franco, María del Carmen Olvera Calvo et al., localizó poco después un dato importante, publicado en el libro Artistas y artesanos a través de fuentes documentales. ${ }^{4}$

6I 2 y 677. Morlete Ruiz, Juan Patricio. Pintor. En las diligencias efectuadas en I 764 para el ingreso de su hija María Antonia de Jesús de 23 años al convento de San Felipe y pobres capuchinas recogieron ser casado en primer matrimonio con María Josefa Careaga, quien fue hija legítima de Nicolás de Cariaga y de Gertrudis Osorio, ya difuntos; ser hijo de Nicolás Morlete y María Manuela Ruiz, difuntos todos españoles y cristianos.

También en esta línea de aportaciones, en 1997, Guillermo Tovar de Teresa, en su obra Repertorio de artistas en México: artes plásticas y decorativas, ${ }^{42}$ completó la información de Armella y Meade con la referencia del bautismo de Juan Patricio el I3 de septiembre de I7I3, sacramento del cual fue padrino Antonio Sánchez Grimaldos, vecino de Querétaro, y dató el testamento mencionado por Francisco de la Maza en I772. Llama la atención la ausencia de referencia a las segundas nupcias, si bien su ficha biográfica en anotación anunciaba la elaboración de una monografía sobre Morlete, aún inédita.

Ligia Fernández y Óscar Flores, discípulos de la historiadora Juana Gutiérrez Haces (autora del estudio introductorio de la obra de Couto ya menciona-

40. María Teresa Terrón Reynolds y Moisés Bazán Huerta, "Obras de arte inéditas en conventos de Plasencia”, Norba-Arte I2 (Universidad de Extremadura, I992): I39-I 40.

4I. Glorinela González Franco, María del Carmen Olvera Calvo et al., Artistas y artesanos a través de fuentes documentales, vol. I, ciudad de México, Colección Fuentes (México: Instituto Nacional de Antropología e Historia, 1994), 285. La referencia mencionada se encuentra asimismo en la tesis de licenciatura de las autoras: "La importancia de las fuentes documentales para el estudio de los artistas y artesanos de la ciudad de México, s. XVI-al XIX" (México: Universidad Nacional Autónoma de México-Facultad de Filosofía y Letras, I99I).

42. Guillermo Tovar de Teresa, Repertorio de artistas en México: artes plásticas y decorativas, 3 vols., vol. II (México: Grupo Financiero Bancomer, 1995), 388-391. La ficha relativa al pintor se acompaña de tres imágenes, una Inmaculada, la Vista de la Plaza Mayor de México con el Real Palacio y la Cathedral con su sagrario y la Vista de La Plaza del Volador, todas, fechadas en I772, se encuentran en el Palacio de San Antón (La Valetta), Malta. 
da), publicaron en 1998 un artículo que recogía los avances conseguidos hasta entonces y, a diferencia de muchos trabajos publicados, presentaba un buen análisis de la trayectoria pictórica del pintor novohispano. ${ }^{43}$ Calificado por ellos como uno de los más importantes de la Nueva España, el breve artículo sintetizaba aspectos de su vida, tales como su presencia en el grupo de artistas que inspeccionaron la imagen de la Virgen de Guadalupe en $175 \mathrm{I}^{44}$ y su participación en 1753 en la fundación de la Academia de Pintura. De sus comentarios, muy en la línea del pensamiento de la maestra Gutiérrez Haces, conviene destacar la pertenencia de Morlete a una corriente innovadora que afectó a las artes de la segunda mitad del siglo XviII, en la cual se pueden establecer semejanzas con los valores pictóricos producidos en Europa en ese momento.

Frente a publicaciones como las de Gómez Eichelmann o Fernández y Flores, resultado no sólo de una acumulación de conocimiento biográfico, contextualización y análisis de nuevas obras aparecidas, siguieron surgiendo otras en las que apenas hubo avance en el conocimiento del pintor. ${ }^{45} \mathrm{La}$ revisión de las noticias publicadas sobre Morlete en esta tercera etapa reporta todavía el uso de fechas extremas dispares. ${ }^{46} \mathrm{~A}$ pesar de ello y de los posibles gazapos detectados, las referencias sobre Morlete Ruiz atrajeron la atención de los historiadores del arte más allá de las fronteras nacionales; ${ }^{47}$ sin embargo, la

43. Ligia Fernández y Óscar Flores, "Juan Patricio Morlete", Veritas (revista del Colegio de Contadores Públicos de México) (julio, I998): 36-37, n. 42.

44. La participación de Morlete en dicha comisión y su opinión al respecto aparecieron en el libro de Miguel Cabrera, Maravilla americana y conjunto de raras maravillas observadas con la dirección de las Reglas de el Arte de la Pintura en la prodigiosa imagen de Nuestra Señora de Guadalupe de México (México: Imprenta del Real y más Antiguo Colegio de San Ildefonso, I756).

45. Marcus Burke, Pintura y escultura en Nueva España. El barroco (México: Azabache, I992), I76; Julia Valdés Landrum, Las artes plásticas en Guanajuato (Guanajuato: La Rana, 2000), 206-2 I0.

46. Ejemplo de ello lo encontramos en los trabajos de Yvette Jiménez de Báez y Rafael Olea Franco, Memoria e interpretación de Al filo del agua, Serie Literatura Mexicana. Cátedra Jaime Torres Bodet V (México: El Colegio de México-Biblioteca Daniel Cosío Villegas, 200o), 248 (quienes dan como fecha de nacimiento la de 1703); Ismael Arturo Montero García, Tepeyac, estudios históricos (México: Universidad del Tepeyac, 2000), I63-164, y José Alcina Franch, Jorge Bernales Ballesteros et al., Historia del arte hispanoamericano, vol. 3 (Madrid: Alhambra, I988), quienes llegaron a extender la vida del pintor hasta 1785 .

47. Inmaculada Rodríguez Moya, La mirada del virrey: iconografía del poder en la Nueva España (Castellón: Universidad Jaume I, 2003), 209, 210 y 212. Esta autora recoge de forma sintética en las fichas 4I, 42 y 44 una breve biografía que sigue básicamente los datos de la 
mayor profundidad sobre su obra y su vida siguió originándose principalmente en estudios realizados en México, que a su vez fueron nutriendo las referencias de los especialistas en el extranjero. De la producción de investigadores del Instituto de Investigaciones Estéticas de la UNAM, contamos en los últimos años con nuevas referencias y comentarios a su obra, como los de Clara Bargellini, al analizar dos obras del pintor (Jesús consolado por Ángeles y Ecce homo) en el catálogo Arte y mistica del barroco ${ }^{48}$ los de Juana Gutiérrez Haces, quien elaboró en el catálogo The Arts in Latin America I492-I820 49 una ficha catalográfica de uno de los cuadros exhibidos de Morlete Ruiz sobre la "Virgen de Guadalupe", y los de Rogelio Ruiz Gomar y Clara Bargellini en Painting a New World. Mexican Art and Life I52I-I82I,, en "La entrada triunfal de Alejandro el Grande" y la atribuida de "Arqueología”, respectivamente.

Junto a las aportaciones, resultado del análisis de obra, contamos recientemente con profundos estudios que van más allá en la contextualización del pintor, su época y los géneros en los cuales incurrió. Notable ejemplo de ello es el estudio de Ilona Katzew, formada tanto en México como en los Estados Unidos, quien al abordar el género de las pinturas de $\operatorname{castas}^{5 \mathrm{I}}$ y al tratar de Juan Patricio Morlete lo analiza paralelamente al trabajo de Miguel Cabrera, de quienes dirá:

Aunque ligados a los artistas de la generación anterior, tanto Morlete Ruiz como

Cabrera introdujeron innovaciones iconográficas que dejaron huella en la pintura

Enciclopedia de México, matizando correctamente el año de defunción y señala que se trata de un discípulo de Ibarra, como especificó Ruiz Gomar en 1995 (cf. n. I2).

48. Arte y mistica del barroco (México: Consejo Nacional para la Cultura y las Artes, 1994), 64 y 68. La ficha biográfica contenida al final del citado catálogo $(369,370)$, correcta en fechas extremas, insistía en que "la escasez de datos sobre su vida y actividades no corresponde a la importancia que debe haber tenido este pintor en su tiempo".

49. Juana Gutiérrez Haces, "Juan Patricio Morlete Ruiz. Virgen de Guadalupe", en The Arts in Latin America I492-I820 (Filadelfia: Philadelphia Museum of Art, 2006), 399, ficha VI-46.

50. Clara Bargallini, Donna Pierce et al., Painting a New World. Mexican Art and Life I52II82I (University of Texas Press: 2004), 73, 268 y 305. Nuevamente la fecha de I7I5 aparecerá en la anotación que sobre el pintor hizo en 2006 María Esther Guzmán Gutiérrez, dentro de la obra de Joaquín Fernández de Lizardi, Amigos, enemigos y comentaristas (México: Universidad Nacional Autónoma de México-Instituto de Investigaciones Filológicas-Centro de Estudios Literarios, 2006), I45, n. 28. Esta autora menciona la existencia de tres dibujos originales del pintor.

5I. Tres de ellos fueron adquiridos por Los Angeles County Museum of Art en Estados Unidos en 20II. Cf. http://collections.lacma.org/node/222684; http://collections.lacma.org/ node/222686, y http://collections.lacma.org/node/222687 
EL GRUPO FAMILIAR DE JUAN GIL PATRICIO MORLETE RUIZ 2 I 3

de castas durante varias décadas; en este sentido pueden considerarse como figuras de transición [...] En resumen las obras de Morlete Ruiz perpetúan la tradición de las pinturas de castas del primer cuarto del siglo Xviı al subrayar el lujo de los personajes, pero añaden sus actitudes y emociones. ${ }^{52}$

Asimismo cabe destacar el trabajo de Paula Mues Orts, La libertad del pincel, quien - a partir de documentación localizada en el Archivo General de Notarías de la Ciudad de México- contextualizó la participación de Morlete en dicho proyecto desde I768, cuando - en unión de Manuel Carcanio, Francisco Antonio Vallejo, Pedro de Quintana y José de Páez, todos con el empleo de profesores de pintura y escultura — otorgó poder ante Antonio José de Olaondo a favor de Luis Bertucat, profesor de pintura, vecino de México, para que solicitase la formación de una academia de pintura y escultura. ${ }^{53}$ Mues Orts ha seguido profundizando sobre el pintor con apreciaciones y datos nuevos en su reciente trabajo "Imágenes de martirio, modelo de salvación: el apostolado del templo de la Santísima de México",54 donde analiza, además, los dos cuadros de Morlete que representan los martirios de san Sebastián y de san Matías, conservados en el mencionado templo.

Recientemente, Francisco Montes González, en su artículo "La paternidad divina hecha hombre. Dos nuevas pinturas de Miguel Cabrera y Juan Patricio

52. Ilona Katzew, La pintura de castas. Representaciones raciales en el México del siglo XVIII (México: Conaculta-Turner, 2004), 94-95.

53. Paula Mues Orts, La libertad del pincel. Discursos sobre la nobleza de la pintura en Nueva España (México: Universidad Iberoamericana, 2008), 4I5-4I6, transcribió el original conservado en el Archivo General de Notarías de la Ciudad de México (AGnCM), Antonio José Olaondo, 472, vol. 3, 239, 4IV-42v (8 de octubre, I768). Dicho documento lo extractó décadas atrás Gabriel Loera Fernández en "El pintor José de Alzíbar. Algunas noticias documentales", Boletín de Monumentos Históricos, primera época, núm. 6 (I98I): 60, n. 6, y fue asimismo mencionado por Katzew, La pintura de castas, 2 Io. Luis Bertucat, como recoge Mues Orts en su estudio, demoró su gestión y en 1769 seguía en la Nueva España. A ello puedo añadir que contrajo nupcias en el Sagrario de México el 8 de marzo de I 769 con Juana Margarita de Lemoene. En el libro de las amonestaciones aparece como originario de la ciudad de París (hijo de Pedro Bertucat y de María Ana Colin) y su esposa, viuda de Pedro de Olaeta, como vecina anteriormente de la villa y puerto de Campeche (ciudad de México, Parroquia del Sagrario, Libro de amonestaciones de españoles, año de 1766 en adelante, sin folio, imagen 92/I I 40).

54. Paula Mues Orts, "Imágenes de martirio, modelo de salvación: el apostolado del templo de la Santísima de México”, Boletín de Monumentos Históricos (México: Instituto Nacional de Antropología e Historia [enero-abril, 2012]): 17-27, n. 24. 
Morlete en Sevilla",55 si bien se limita a las características del pintor ya referidas por Toussaint, aporta un breve análisis de una nueva obra localizada que representa a san José con el Niño, fechada hacia 1765.

Las múltiples pinturas de temática religiosa, los paisajes, las representaciones de los cuadros de castas, los retratos y las composiciones alegóricas, todas ellas obras citadas a lo largo de la bibliografía consultada sobre Morlete, en ese otro ejercicio "casi-genealógico" de conformación de una biografía, constituyen una muestra de la riqueza de su producción, aspecto que rompe con la vieja idea de una producción limitada. Asimismo, el volumen representa un reto para los historiadores del arte al conformar un catálogo, en el cual habrá de sortearse la dificultad de que gran parte de su producción se perdiós ${ }^{6} \mathrm{y}$ otra se encuentra en colecciones particulares, muchas de ellas desconocidas. Sirva como ejemplo el retrato de Carlos III de tamaño natural que se conserva en la ciudad de México (figs. I y 2). ${ }^{57}$

\section{La reconstrucción familiar de Morlete Ruiz}

Una rápida visita a las fuentes sacramentales

Gracias a la labor desarrollada por la Iglesia de Jesucristo de los Últimos Días por medio del portal Familysearch y a la puesta en línea de gran parte de los registros sacramentales mexicanos digitalizados, no fue difícil localizar las actas matrimoniales de Juan Gil Patricio Morlete Ruiz en los libros de la parroquia del Sagrario Metropolitano de la Ciudad de México, mismas que ya habían difundido, como se indicó párrafos atrás, Virginia Armella, Mercedes Meade y Guillermo Tovar. La inscripción del matrimonio, como ocurre en la

55. Francisco Montes González, "La paternidad divina hecha hombre. Dos nuevas pinturas de Miguel Cabrera y Juan Patricio Morlete en Sevilla", Atrio I5-I6 (2009-2010): I77-I86.

56. Hay varios testimonios de pinturas desaparecidas de Morlete; uno de ellos se refiere a las que existieron en el antiguo Carmen de Celaya (Francisco Eduardo Tresguerras, "Celaya. Templo de N. S. del Carmen”, en Diario de México, t. IX, n. I I7, miércoles I 4 de diciembre, I808, 686), y el otro, a varias pinturas de retablo en el Colegio de San Ignacio de Loyola (Las Vizcaínas). (Sobre estas últimas Leonor Labastida Vargas ofrecerá nueva información inédita sobre Morlete en su tesis de doctorado en preparación "El patrocinio artístico vasco en la Nueva Espańa: la Cofradía de Nuestra Señora de Aránzazu y el Colegio de San Ignacio de Loyola, Vizcaínas".

57. Veáse la descripción del cuadro realizada por Pedro Ángeles en el “Ápendice”. 


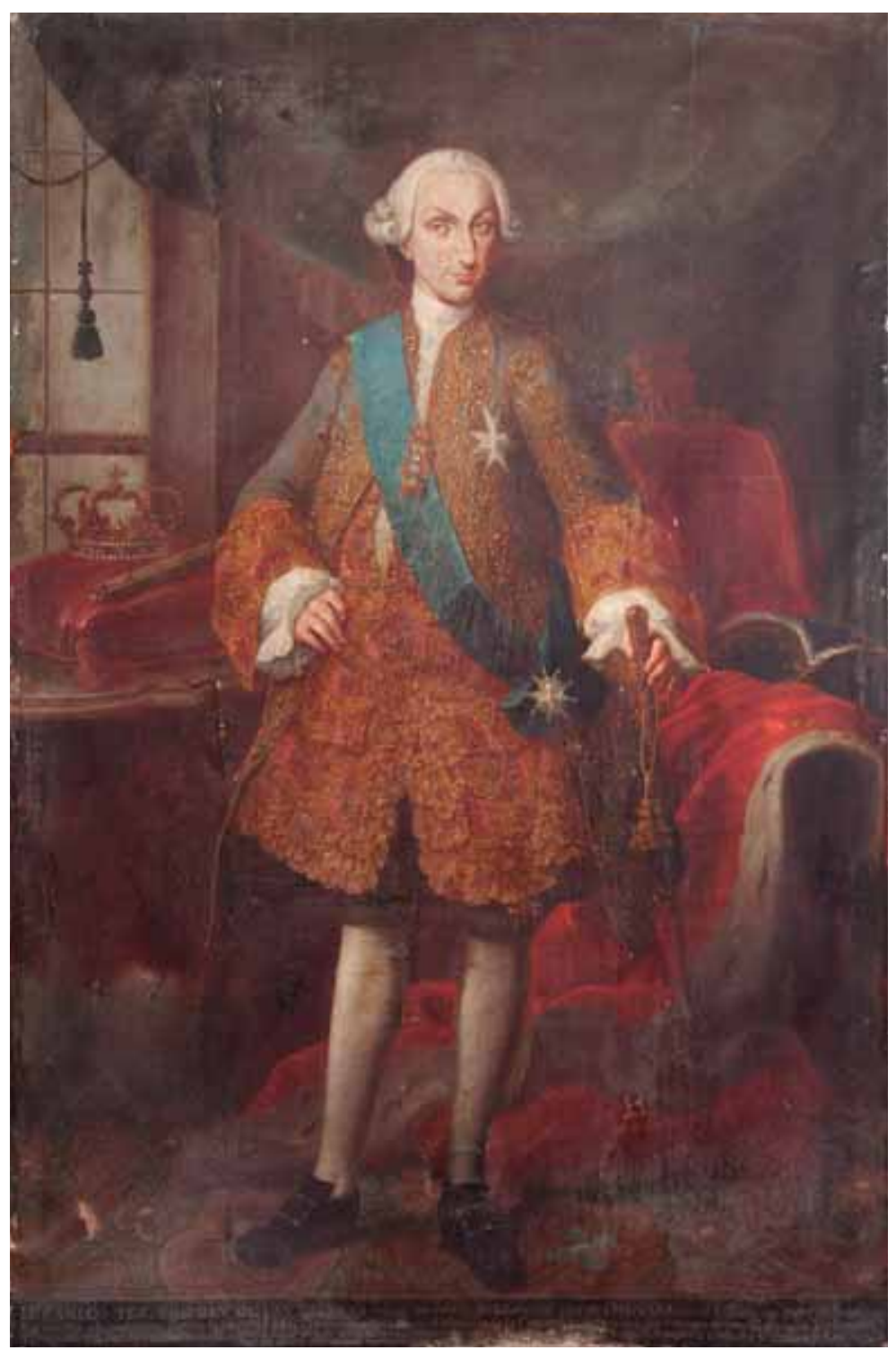

I. Juan Gil Patricio Morlete Ruiz, Retrato de Carlos III, I760, 210 $140 \mathrm{~cm}$. Colección Francisco Luis de Yturbe, ciudad de México. Foto: Pedro Ángeles Jiménez. Archivo Fotográfico Manuel Toussaint, IIE-UnAm. 


\section{6}

JAVIER SANCHIZ

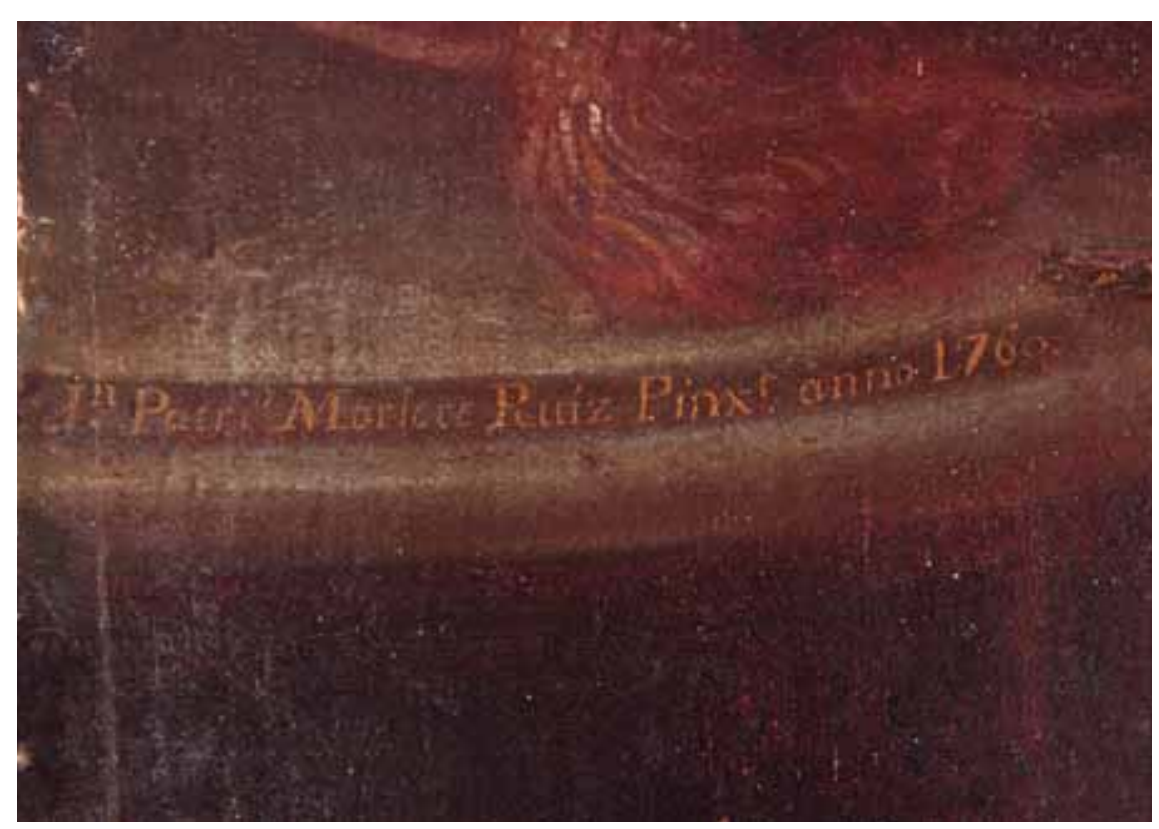

2) Juan Gil Patricio Morlete Ruiz, detalle del Retrato de Carlos III, firmado: In Patrio Morlete Ruiz Pixt. Anno 1760. Foto: Pedro Ángeles Jiménez. Archivo Fotográfico Manuel Toussaint, IIE-UNAM.

mayoría de los registros del siglo xvinI, es muy escueta y no ofrece el nombre de los padres de los contrayentes (fig. 3).58

La información de filiación pudo obtenerse en el correspondiente libro de las amonestaciones.

58. Sagrario Metropolitano de la Ciudad de México, Libro de matrimonios de españoles [del Sagrario de la Iglesia Catedral de México, que empieza desde primero de enero de mil setecientos treinta y tres años en adelante], 24V, n. I8, imagen 284/986. Junto a la referencia de libro y folio se ha consignado en las actas relativas al pintor el número de la imagen digitalizada para su rápida ubicación en el portal de Familysearch > México > México, Distrito Federal, registros parroquiales y diocesanos, I5I4-I970 > Asunción Sagrario Metropolitano (Centro) > libro correspondiente > imagen. Las amonestaciones se encuentran dentro del rubro de informaciones matrimoniales. 


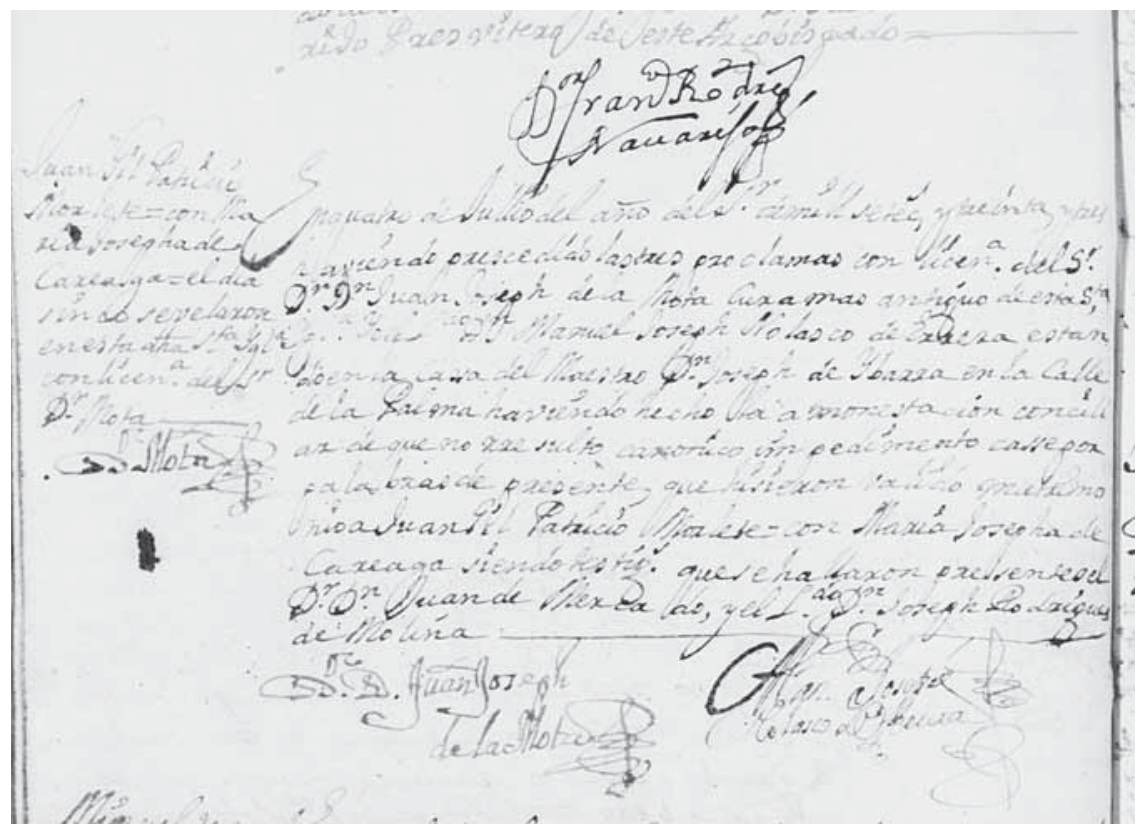

3. Inscripción de las primeras nupcias de Juan Gil Patricio Morlete Ruiz, I733. Parroquia del Sagrario Metropolitano, ciudad de México.

[Al margen: licencia de doctor Mota para matrimonio a el bachiller don Manuel Nolasco en 4 de jullio de 1733 años]. Juan Gil Patricio Morlete, español, natural de la villa de San Miguel el Grande y vezino de esta ciudad de quatro ańos a esta parte hijo legítimo de Nicolás Francisco Morlete y de María Manuela Ruiz. Con María Josefa de Careaga, española, natural y vezina de esta ciudad hija legítima de Nicolás de Careaga y de Gertrudis Osorio. ${ }^{59}$

Respecto a la ceremonia registrada en el libro de matrimonios, se desprende que éste se efectuó el día 4, habiendo precedido las tres proclamas, con la licencia del señor doctor Juan José de la Mota, cura más antiguo del Sagrario, oficiando el licenciado Manuel José Nolasco de Herrera. El acto tuvo lugar "en la casa del maestro don José de Ybarra, en la calle de la Palma, habiendo

59. Sagrario Metropolitano de la Ciudad de México, Libro de amonestaciones (I694/I734), foja I69, n. I9, imagen I029/1046. 

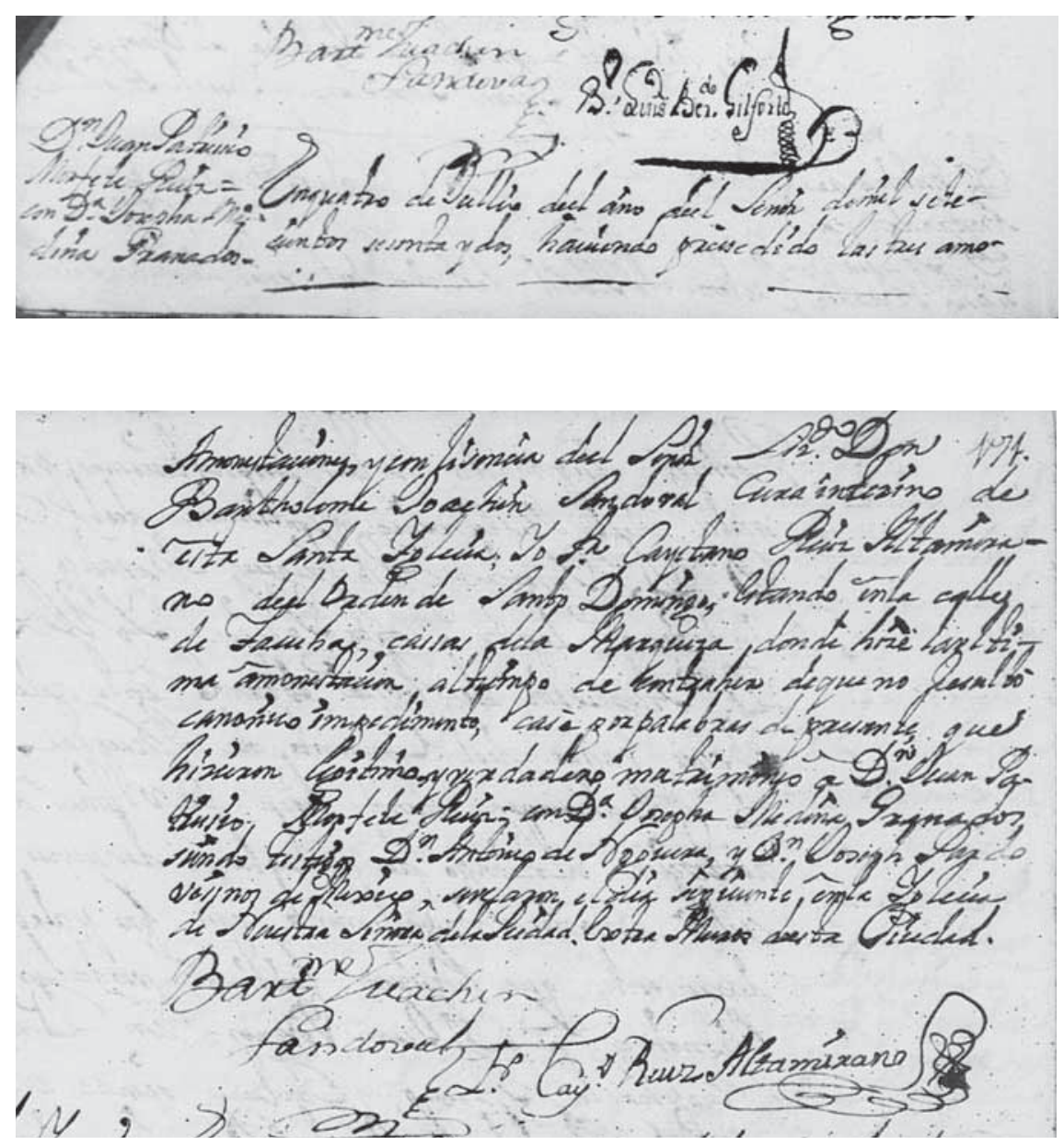

4a y b) Inscripción en el Libro de matrimonios de las segundas nupcias de Juan Gil Patricio Morlete. Sagrario Metropolitano de la Ciudad de México.

hecho la amonestación conciliar de que no resultó canónico impedimento". Fungieron como padrinos el doctor Juan de Mercado y el licenciado José Rodríguez de Molina. El día 5, en la parroquia del Sagrario Metropolitano de la Ciudad de México, recibieron las bendiciones nupciales.

Los padres de la primera esposa de Morlete Ruiz fueron Nicolás Careaga (apellido que también aparece escrito Cariaga) y Gertrudis Osorio, casados 
en la parroquia del Sagrario Metropolitano de la Ciudad de México el 3 de septiembre de 1724. Su inscripción en el libro de matrimonios de castas permitió averiguar que él era castizo y ella española, ${ }^{60}$ y sabemos de la existencia de al menos dos hermanos: José Maximino, bautizado en la Santa Veracruz el I8 de enero de I728, y María Ignacia, nacida el 23 de septiembre de 1733 y bautizada en el Sagrario el 29. Este origen, en el grupo de castas, de la esposa de Morlete fue "maquillado" en los registros de matrimonios. Ni qué decir tiene que la adscripción en el libro de españoles obedecía principalmente a dos situaciones: la primera, la blancura de la persona registrada, entendiendo por blancura que el componente racial indígena o negro hubiera sido diluido por la mezcla racial blanca, y la segunda y más generalizada, que el modus vivendi de los contrayentes se ajustara a los patrones sociales de la población española.

La defunción de Josefa Careaga, como mencionaron Armella y Meade, no se localizó en el Sagrario, a lo cual puedo añadir que no está ni en el libro de españoles ni en el correspondiente a las castas; y tampoco la pude localizar en los libros de Santa Catarina, la Santa Veracruz y San Miguel Arcángel. La búsqueda la realicé teniendo como fechas extremas el nacimiento del último de los hijos del matrimonio — por si hubiese muerto de parto- y el segundo matrimonio de Morlete.

Sin haber podido precisar desde cuándo era viudo Juan Gil Patricio Morlete, contrajo segundas nupcias asimismo en la parroquia del Sagrario Metropolitano de la Ciudad de México, donde también quedó registro de las amonestaciones (fig. 4).

[Al margen izquierdo: Y tuvo licencia general de el señor Sandoval en 4 de julio de 62. Y traxo despacho de el señor provisor para la dispensa de las 24 horas, la que queda con las amonestaciones en su legajo]. Don Juan Patricio Morlete Ruis, español, vecino de esta ciudad, viudo de doña María Josepha Careaga con doña Josepha Medina Granados, española, natural y vecina de esta ciudad. Hija lexítima de don Joachín Medina Granados y doña Anna Sevilla. [Al margen derecho: En 27]. ${ }^{61}$

60. Sagrario Metroplitano de la Ciudad de México, Libro de matrimonio de castas, foja 59, imagen 272/IO2I.

6I. Sagrario Metropolitano de la Ciudad de México, Libro de amonestaciones (1734-I765), foja 6I, imagen 939/1084. 


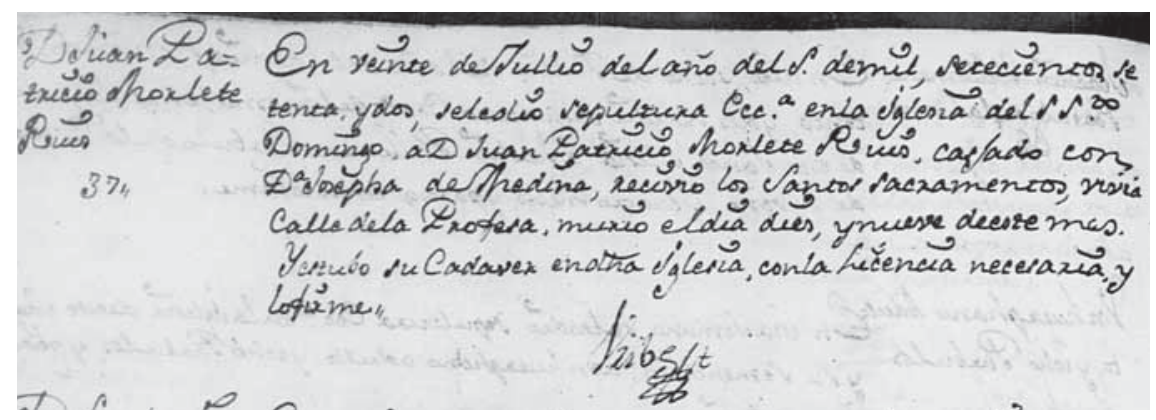

5. Inscripción de la muerte de Morlete. Parroquia del Sagrario Metropolitano de la Ciudad de México.

El acto del matrimonio tuvo lugar en las casas de la marquesa, sitas en la calle de Tacuba, asentándose el sacramento en el Sagrario Metropolitano de la Ciudad de México, el 4 de julio de I762, con Josefa Medina Granados, española, natural y vecina de la ciudad de México, hija legítima de Joaquín Medina Granados y Ana Sevilla. ${ }^{62}$ Los testigos de la ceremonia fueron Antonio de Noguera y José Pardo. Las bendiciones nupciales las recibieron en la iglesia de Nuestra Señora de la Piedad.

La nueva sociedad conyugal duró solamente ıo años, pues Juan Gil Patricio Morlete Ruiz falleció en la ciudad de México el is de julio de I772; vivía entonces en la calle de la Profesa, y fue enterrado el día 20 en la iglesia de Santo Domingo. ${ }^{63}$ El año de fallecimiento, deducido del testamento datado por Tovar de Teresa, queda corroborado con el registro de su defunción, corrigiendo las numerosas referencias a su muerte que pulularon entre 1770 y 1790 (fig. 5).

El número de hijos del matrimonio y las relaciones de compadrazgo

De los ocho hijos (tres varones y cinco mujeres) mencionados por Toussaint, sabíamos sus nombres por el padrón de I753. Juan (I735), José (I747), Fran-

62. Sagrario Metropolitano de la Ciudad de México, Libro de matrimonios de españoles, I70v y I7I, imagen $534 / 839$.

63. Sagrario Metropolitano de la Ciudad de México, Libro de defunciones, I82v, partida 37, imagen 386/953. 
cisco (I75I), María I (I74I), María II (I743), María III (I744), María IV (I745) y María V (I753). Ante la dificultad de cotejar el padrón de 1767 por estar en una colección particular desconocida, la búsqueda de los bautismos de los hijos habidos en los dos matrimonios de Juan Patricio Morlete reportó un total de I9. De ellos, la mayoría debe de haber fallecido en la infancia, y sólo me consta que tres contrajeron matrimonio y tuvieron sucesión. El fallecimiento del pintor en I772 dejaría huérfana a la última de sus hijas con sólo cuatro meses y seis días de vida. De los diez nietos localizados, Juan Patricio apenas si conoció al primogénito de ellos, nacido en septiembre de I77I, del cual queda sucesión hasta nuestros días.

Poder establecer sin temor a equívoco todas las relaciones de compadrazgo que pudo haber tenido una persona a lo largo de su vida conlleva invariablemente a revisar todos y cada uno de los bautizos efectuados, tanto en un amplio margen geográfico como en un largo periodo de tiempo. Es posible, gracias a la reconstrucción familiar realizada, trazar al menos las redes de afinidad — compadrazgo — que Juan Patricio Morlete Ruiz formalizó desde su grupo familiar; debido a la prolijidad de familia, contó con I8 compadres:

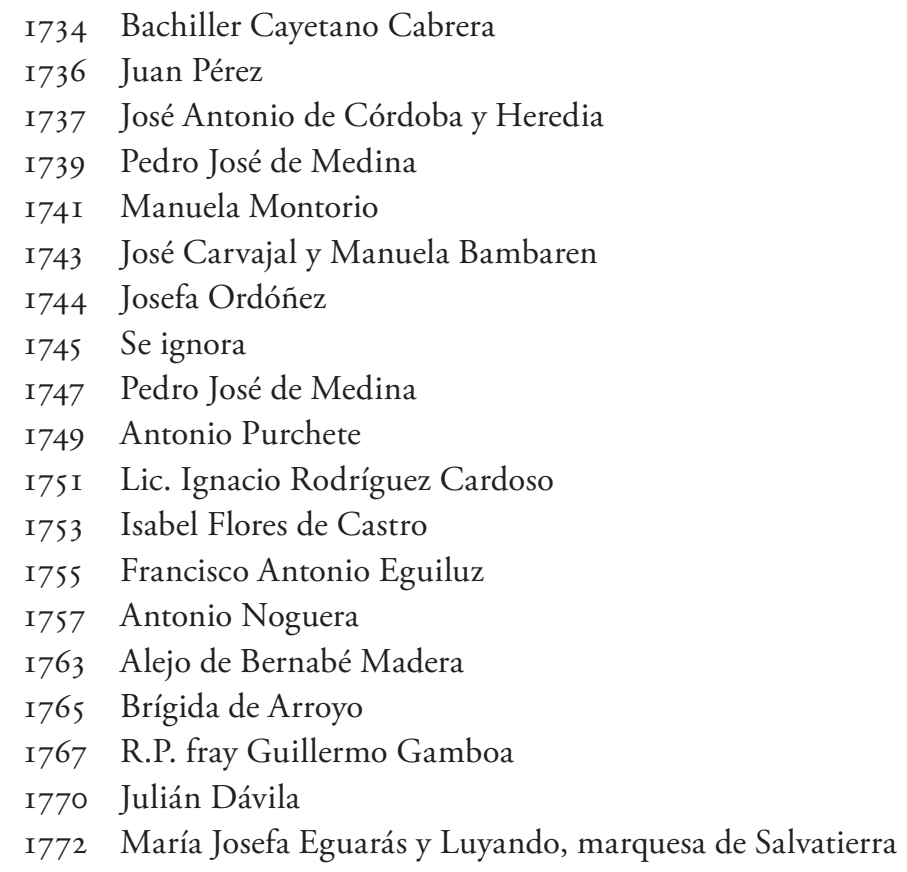


No obstante el largo listado de sus compadres, poco he podido averiguar sobre los mismos. La mayoría tuvieron el tratamiento del "don/doña". Sólo cuatro no: de éstos, sabemos que José de Carvajal fue esposo de Manuela Bambaren Lanzarote, con quien se había casado en México (Sagrario) el 5 de mayo de I738. Los Bambaren Lanzarote estuvieron vinculados a otros pintores novohispanos; así, su sobrina y homónima María Manuela Bambaren se casaría en 1783 en Puebla con el pintor Jacobo Monfort Villegas. Otro de los padrinos, Alejo de Bernabé Madera, fue suegro de José Marrugat y Bolón, catalán de la villa de Igualada, avecindado en México y vinculado al mundo del comercio y los negocios.

El primero de los compadres escogidos fue el célebre Cayetano Cabrera Quintero, presbítero, abogado, escritor fecundo e investigador laboriosísimo, autor del "Escudo de Armas de México", 64 el cual, junto con Francisco Antonio Eguiluz, clérigo presbítero del arzobispado, y fray Guillermo Gamboa, comisario general de la orden de San Juan de Dios, pudo ser identificado dentro del estamento eclesiástico.

Pedro José de Medina (el único que repitió compadrazgo) se había casado en México (Sagrario) el 2 de mayo de 1723 con María Dominga de Villarreal (hija de Juan Villarreal y Manuela Esquivel Cervantes). El licenciado Juan Ignacio Rodríguez Cardoso era esposo de Rosa Vázquez, y ambos, suegros de Juan Manuel de la Riva Tagle y Blanco. Respecto a Josefa Ordóńez, hay dudas de que se trate de la Josefa Ordoñez ${ }^{65}$ que alcanzó gran renombre en el teatro de la ciudad de México en I747, pues en I744 apenas tendría I5 años.

Por su prestigio social, destaca de todo el grupo la marquesa de Salvatierra; su presencia podría esclarecer que fue en su residencia donde se realizó la ceremonia de las segundas nupcias de Juan Gil Patricio Morlete, quien como se anotó en el acta de matrimonio, residía en la calle de Tacuba.

No deja de ser todavía una hipótesis que la segunda esposa del pintor haya pertenecido a la familia ampliada de la marquesa, como también pudo haber sido deuda de Pedro José de Medina, ya citado. De lo que no cabe ninguna duda es que el estatus social de Morlete subió considerablemente a partir de este segundo enlace, pues si bien en las partidas de bautismo de los hijos de su

64. Véase sobre él la biografía escrita por Francisco Sosa en Biografías de mexicanos distinguidos (México: Porrúa, I985), iog y i Io.

65. María del Carmen Vázquez Mantecón, Los días de Josefa Ordóñez (México: Universidad Nacional Autónoma de México, 2005). 
EL GRUPO FAMILIAR DE JUAN GiL PATRICIO MORLETE RUIZ 223

primer matrimonio sólo en 1739 se asentó al pintor con el prefijo de "don", éste apareció en todos los bautismos de su segundo matrimonio.

La reconstrucción familiar (genealogía descendente)

Nicolás (Francisco) Morlete, de calidad español. Casó en San Miguel el Grande (San Miguel Arcángel) el I4 de febrero de I708 con Manuela Ruiz, india. Fueron padres, al menos, de:

- I) Juan Gil Patricio Morlete Ruiz, nacido el 30 de agosto de I7I3 en San Miguel el Grande (actual San Miguel de Allende, en el estado de Guanajuato) (B: San Miguel Arcángel el I3 de septiembre). Falleció en México (Sagrario) el I9 de julio de I772, en su domicilio sito en la calle de la Profesa. Fue enterrado el 20 en la iglesia de Santo Domingo. Contrajo primeras nupcias en México (Sagrario) el 4 de julio de 1733 con María Josefa Careaga Osorio, nacida en México (hija de Nicolás Careaga y Gertrudis Osorio, casados en el Sagrario de la ciudad de México el 3 de septiembre de 1724). Fueron padres de:

○ I. Juan Manuel Cayetano Morlete Careaga, nacido en la ciudad de México el 2 de julio de 1734 (B: Sagrario el 4).

$\bigcirc$ 2. José Vicente Irineo Morlete Careaga, nacido en la ciudad de México el 3 de abril de 1736 (B: Sagrario el 8).

- 3. José Manuel Morlete Careaga, nacido en la ciudad de México el 25 de diciembre de 1737 (B: Sagrario el 28).

- 4. María de Jesús Rosalía Morlete Careaga, nacida en la ciudad de México el 22 de septiembre de 1739 (B: Sagrario el 25). Contrajo matrimonio en México (Sagrario) el 8 de febrero de 1774 con Francisco Javier de Arosqueta y de la Campa-Cos, nacido en Durango, Nueva Vizcaya, el 7 de diciembre de 174I (hijo de Sebastián de Arosqueta Carrasco, nacido en la ciudad de México, y de Ana María de la Campa-Cos, nacida en Durango, Nueva Vizcaya, donde asimismo se casaron el 20 de febrero de 1737). Fueron testigos del matrimonio José Antonio Morlete y Antonio Romero. Fueron padres de:

- a) Josefa Ignacia Simona de Arosqueta Morlete. Nació en la ciudad de México el 28 de octubre de 1774 (B: Sagrario el 30).

- b) José Ignacio María Emeterio Antonio de Arosqueta Morlete. Nació en la ciudad de México el 3 de marzo de 1777 (B: Sagrario el 4). 
- c) José María Javier Tomás de Arosqueta Morlete. Nació en la ciudad de México el 2I de diciembre de 1778 (B: Sagrario el 23).

- d) María Manuela Javiera Epigmenia de Arosqueta Morlete. Nació en la ciudad de México el 24 de marzo de 1780 (B: Sagrario el 26).

- 5. María Antonia de Jesús Morlete Careaga, nacida en la ciudad de México el 2I de junio de I74I (B: Sagrario el 29). Vivía en I753. Religiosa.

○ 6. María Faustina de los Reyes Morlete Careaga, nacida en la ciudad de México el 6 de enero de 1743 (B: Sagrario el II). Vivía en 1753.

○ 7. María Micaela de la Luz Antonia Morlete Careaga, nacida el 29 de septiembre de 1744 en la ciudad de México (B: Sagrario el 2 de octubre). Vivía en 1753.

○ 8. María Morlete Careaga. Nació ca. I745. En el padrón de 1753 aparece avecindada en casa de sus padres con ocho ańos de edad.

9. José Antonio Morlete Careaga, nacido en la ciudad de México el 3 de junio de I747 (B: Sagrario el 6). Se casó el I7 de septiembre de I770 en México (Santa Veracruz), con María Josefa Vázquez Torres, nacida en la ciudad de México (hija de Martín Vázquez y de María Josefa Juana de Torres). Padres de:

- a) Francisco José María Morlete Vázquez. Nació en México el I4 de septiembre de I77I (B: Santa Cruz y Soledad el I8). Contralor del Real Hospital de Perote. Casado el I de marzo de I79I en México (Santa Veracruz), con Faustina Vicenta Sánchez Rodríguez, nacida en México (hija de Matías Sánchez y María Antonia Rodríguez). Padres de los siguientes siete hijos y en cuya generación el apellido fue modificado a Morlet: $\square \quad$ I) Domingo Santiago Agustín Morlete Sánchez, nacido el 4 de agosto de 1793 en la ciudad de México (B: Sagrario el 6).

$\square \quad$ 2) Mariano Morlete Sánchez, nacido el 4 de septiembre de 1799 en Perote, Veracruz (B: San Miguel Arcángel el 6). General de brigada del Ejército mexicano. Casado in articulo mortis el 3 de noviembre de 1845 en México (San Miguel Arcángel) con Dolores Salcedo Guevara, nacida en Texcoco ca. I795 (hija de José Salcedo y de Juana Guevara). Con sucesión.

- 3) José Luis de Santa Rosalía Morlete Sánchez, nacido el 4 de septiembre de 1799 en Perote, Veracruz (B: San Miguel Arcángel el 6). Casado el Is de julio de I830 en México (San Miguel Arcángel), con María Guadalupe Pardiñas Nogueira (hija de Francisco Pardiñas Villar de Francos Otero y de María Luisa Nogueira). 
EL GRUPO FAMILIAR DE JUAN GIL PATRICIO MORLETE RUIZ 225

Con descendencia, en la cual recayó el mejor derecho genealógico a la sucesión del condado de Castelo.

$\square \quad$ 4) Ana María Cornelia Cipriana Morlete Sánchez, nacida el I7 de septiembre de i8or en Perote, Veracruz.

口 5) María Guadalupe Morlete Sánchez, nacida ca. I8o6. Contrajo matrimonio el 24 de octubre de I 826 en San Andrés Chalchicomula, Puebla, con Ramón Cartabuena Alcedo, nacido ca. 1797 (hijo de Esteban Cartabuena y de Josefa Alcedo Cordero). Con sucesión.

$\square$ 6) Francisco Pascasio Morlete Sánchez, nacido en I808 en Perote, Veracruz (bautizado en San Miguel Arcángel el 25 de febrero de I808). Casado el 5 de diciembre de I844 en la ciudad de México (San Miguel Arcángel) con María del Carmen Jacinta Crespillo García de la Cruz, nacida en I823 en la ciudad de México (B: Sagrario el I 4 de septiembre) (hija de Joaquín Crespillo y de Dolores García de la Cruz). Con descendencia.

$\square \quad$ 7) Matiana Josefa Morlete Sánchez, nacida en Perote, Veracruz, el 26 de febrero de I809.

- b) Ana María Dolores Teodora Morlete Vázquez, nacida el I de abril de 1773 en la ciudad de México (B: Sagrario el 5).

- c) Ana María Josefa Evarista Morlete Vázquez, nacida en la ciudad de México el 26 de octubre de 1774 (B: Sagrario el 28).

- d) María de Guadalupe Ana Secundina Morlete Vázquez, nacida el 2 de julio de 1776 en la ciudad de México (B: Sagrario el 4). Contrajo matrimonio el 7 de julio de 1795 en México (Sagrario), con Bartolomé Truco Ceno (hijo de Ángel Truco y Benita Ceno). Administrador de rentas nacionales de Tlaxcala. Viudo en primeras nupcias de María Manuela Suárez Espinosa, con la que se había casado el 28 de septiembre de I79I en México (Sagrario).

○ Io. María Gertrudis Guadalupe de Jesús Ferdinanda Morlete Careaga, nacida el 30 de mayo de 1749 en la ciudad de México (B: Sagrario el 2 de junio).

○ II. Francisco Antonio Mariano Morlete Careaga, nacido el 2 de abril de I75I en la ciudad de México (B: Sagrario el 4).

○ I2. María Josefa de Jesús Olaya Morlete Careaga, nacida en la ciudad de México el 5 de marzo de 1753 (B: Sagrario el I3). Casada el 17 de agosto de 1783 en México (Sagrario), con Juan Ignacio de Arosqueta y de la Campa-Cos (hermano de Francisco Javier, arriba mencionado). Padres de: 
- a) Agustín Pioquinto Mariano José Domingo Ignacio de Arosqueta Morlete, nacido en la ciudad de México el 5 de mayo de I784 (B: San Sebastián el 6).

- b) José María Crescencio Joaquín Juan Bautista de Arosqueta Morlete, nacido el is de abril de 1786 en la ciudad de México (B: San Sebastián el 2I).

- c) Ana María Dolores Josefa de Arosqueta Morlete, nacida el i de marzo de 1788 en la ciudad de México (B: San Sebastián el I3).

I 3 . José Joaquín Mariano Morlete Careaga, nacido en la ciudad de México el I6 de marzo de I755 (B: Sagrario el i9).

○ I4. María de Jesús Dolores Ignacia Gervasia Morlete Careaga, nacida el I9 de junio de 1757 en la ciudad de México (B: Sagrario el 2I).

Juan Gil Patricio Morlete Ruiz contrajo segundas nupcias en México (Sagrario) el 4 de julio de 1762 con María Josefa Medina Granados, quien, según la inscripción de las amonestaciones, había nacido en México y era hija de Joaquín Medina y Granados y de Ana Sevilla. ${ }^{66}$ Viuda, adquirió en 1784 la hacienda de Legaria. ${ }^{67}$ De este segundo enlace nacieron:

I 5 . Manuel José María Ignacio Domingo Morlete-Ruiz Medina, nacido en México el I2 de mayo de 1763 (B: Sagrario el I4).

○ I6. María de Jesús Dolores Guadalupe Antonia Macedonia Morlete-Ruiz Medina, nacida el I2 de septiembre de I765 en México (B: Sagrario el I4).

- I7. José Ignacio Domingo Esteban Morlete-Ruiz Medina, nacido en la ciudad de México el 3 de agosto de 1767 (B: Sagrario el 9).

○ I8. José Vicente Rudesindo Cayetano Morlete-Ruiz Medina, nacido el 2 de marzo de 1770 en la ciudad de México (B: Sagrario el 4).

○ I9. María de Jesús Josefa Vicenta Matilde Juana Evangelista Morlete-Ruiz Medina, nacida en la ciudad de México el I 4 de marzo de 1772 (B: Sagrario el $\mathrm{I} 7$ ).

- II. Juan Manuel Cristóbal Morlete Ruiz, nacido en Celaya, en el actual estado de Guanajuato, y allí bautizado el 27 de septiembre i7i6.

66. A pesar de lo anterior, no he localizado el matrimonio de sus padres ni la presencia de más miembros del apellido "Medina y Granados" en Nueva España. No descarto la posibilidad de que hubiese un error involuntario en quien realizó la inscripción en el libro de amonestaciones.

67. María del Carmen Reyna, Tacuba y sus alrededores. Siglos XVI-XIX (México: Instituto Nacional de Antropología e Historia, I995), 38. 
EL GRUPO FAMiliar DE JUAN Gil PATRICIO MORLETE RUiz 227

Con la presente reconstrucción familiar queda trazada la extensión del grupo familiar biológico del pintor y gran parte de su descendencia, alguna de la cual enlazaría con sucesores de la nobleza titulada en la Nueva Espańa; asimismo las fechas extremas de su vida comprobadas documentalmente y que tan confusas aparecían en las referencias publicadas sobre el pintor. Las relaciones de afinidad establecidas por Morlete remiten, a su vez, a un pequeño universo que puede haber influido en otras redes con implicaciones profesionales todavía por explorar. $\$$ 


\section{Apéndice}

Un retrato desconocido de Carlos III

En I990, Elisa Vargaslugo publicó un artículo en el cual presentó las pinturas más importantes, conocidas hasta ese momento en torno a la efigie de Carlos III. Entonces comentó que, frente al escaso número de imágenes de la realeza española existentes en México conservadas hasta nuestros días, mucho sorprendía que del mencionado monarca hubiera podido reunir is retratos en pintura, "con la certeza de que deben existir muchos más diseminados en los templos de nuestro territorio, o conservados en colecciones particulares, como algunos de los que aquí se mencionan por primera vez". I Eso sin contar la riquísima iconografía carlista derivada de grabados, dibujos, yesos, troqueles y medallas, conjunto que en sí mismo daría motivo para una indagación más profunda.

Entre las obras más relevantes citadas por la mencionada autora, destacan las ejecutadas por Miguel Cabrera (I760), ${ }^{2}$ Ramón Torres (ca. I760), Francisco Martínez ${ }^{3}$ y José de Alcíbar (I774), ${ }^{4}$ que entre el corpus mencionado serían las firmadas por algún pintor novohispano, ańadiéndose a ellas otra importante pintura de uno de sus contemporáneos, se trata de un Retrato de Carlos III firmado y fechado por Juan Gil Patricio Morlete Ruiz en I760.

Como se aprecia, resulta interesante considerar que tres de ellas fueran ejecutadas en los albores del reinado de Carlos III, con lo cual podría presumirse que la difusión de la real efigie mostró ecos puntuales, los cuales comenzarían desde el momento mismo de la jura y las consecuentes ceremonias de exaltación al trono realizadas a lo largo y ancho de los reinos y territorios del vasto imperio espańol. Otro rasgo interesante resulta la forma en que la iconografía más temprana también muestra cierta filiación con el retrato oficial ejecutado por Anton Raphael Mengs, quien aún antes de realizar su versión pintada pudo

I. Elisa Vargaslugo, "Los retratos de Carlos III en la Nueva España”, en Charles III: Florida and the Gulf (Miami: Count of Galvez Historical Society, I990); I08-I22. Efectivamente, nuevos hallazgos motivarían la puesta al día del citado artículo publicando una versión con adiciones en: Anuario 1988-1989 del Seminario de Cultura Mexicana (México, Seminario de Cultura Mexicana, I99I), I07-I24.

2. Museo del Colegio de las Vizcaínas.

3. Ambas localizadas en el Museo Nacional de Historia.

4. Parte del acervo de la Pinacoteca de la Iglesia Profesa. 
llevar a cabo dibujos que circularon con presteza para tal fin. La obra de Morlete resulta original y para acotar en ello es imprescindible leer su inscripción:

$\mathrm{D}^{\mathrm{n}}$ Carlos Tercero, rey de las Españas. nació en veinte de enero del año de I7 I 6; y se Juró en España en onze de septiembre de 1759 a su pedimento declaró la Santidad del $S^{t}$ Clemente Dezimotercio, el Mysterio de la Concepción de $\mathrm{N}^{\text {ra }} S^{\text {ra }}$ por patrona universal de todos los Reynos y Dominios, el q. juró Su Magestad en su Corte e hizo Jurar en toda su Corona; y consiguió para toda ella Oficio [...] M[...] de la Religión Seraphica. Adjudicó y renovó a su Real Patronato este convento de la Concep ción añadiéndole al [...] de [...]

Como las demás, esta pintura también conmemora el advenimiento al trono del rey, pero presenta además dos detalles fundamentales: que la obra perteneció al convento de la Concepción y que festeja asimismo la declaración del papa Clemente XIII, promovida por Carlos III, para nombrar el misterio de la Concepción de la Virgen como patrona de todo el imperio hispánico. Junto al ascenso al trono por parte del rey, se lograba un singular beneficio alcanzado por la piedad hispana en beneficio de una de sus principales devociones, situación que la orden seráfica festeja en la Nueva España con la ejecución de este retrato.

Aparece el monarca de cuerpo entero, ataviado con camisa blanca de discretos holanes en las mangas y en el pecho, que contrasta con los ostentosos brocados del resto de su indumentaria. Destaca en el pecho una banda de hermoso azul el cual si bien puede ceñirse a simbolismos relacionados con la propia monarquía como el Toisón de Oro y la gran cruz de la orden del Espíritu Santo (L’Ordre du Saint-Esprit) —que ese mismo año, I760, le entregó Luis XV, rey de Francia-, no deja de ser el color de la devoción concepcionista.

De hecho, esta cuestión distingue también a la obra de Morlete cuyo Carlos III, alejándose del modelo oficial definido desde la corte española a partir de la obra de Mengs, encuentra más relación con el retrato de cuerpo entero de Luis XV luciendo la cruz de la orden del Espiritu Santo, firmado y fechado por Louis-Michel van Loo en 1763,5 aunque la versión novohispana enriquece el significado imperial con la presencia del trono, cetro y corona.

5. Al parecer localizado en el Museo de Bellas Artes de Grenoble. 
El rostro de Carlos III resulta impresionante, la nariz prominente, ojos azules y boca delgada evocan en todo la fisonomía del monarca, sólo parecería más joven de los 44 años que tenía al momento de llevarse a cabo esta efigie cuyos valores plásticos vuelven a revelar la gran originalidad y talento de Juan Gil Patricio Morlete Ruiz.

Pedro Ángeles Jiménez, IIE-UNAM 